\title{
Diffraction Methods to Analyse Cementations Materials
}

\section{$\underline{\text { Xabier Mikel Turrillas Maisterra }}$}

(ICMAB, ALBA - Spain)

The use of diffraction methods to determine existent crystalline phases in construction materials and their eventual quantification is explained. General aspects of the method with some practical applications are described. The different types of ancillary available today, such as conventional diffractometers in different operation modes (reflection and transmission) or instruments of large-scale facilities (synchrotron and neutron sources) are expound. The practice and implementation of the method is treated with some detail. Finally some examples of utilization in control of cement manufacture, assessment of building materials to be used in public works, appraisal of curing process and analysis of the degradation in concrete and other construction materials in connection with cultural heritage are reviewed. 